\title{
O Brasil e o regionalismo continental frente a uma ordem mundial em transição
}

Brazil and American regionalism in a changing world order

LUIZ A. P. SOUTO MAIOR*

Rev. Bras. Polít. Int. 49 (2): 42-59 [2006]

\section{Introdução}

Durante quase toda a segunda metade do século XX, a política externa brasileira foi marcada por duas constantes - a preocupação com o desenvolvimento econômico e, no contexto da Guerra Fria, a fidelidade à aliança ocidental. Era, em última análise, a política internacional de um país em desenvolvimento ligado ao bloco ocidental. Inevitavelmente, o peso relativo atribuído a cada um daqueles condicionantes básicos, a percepção de como os dois interagiam e a maneira de conciliá-los variou de acordo com o jogo das forças políticas internas, determinando conseqüentemente algumas oscilaçôes numa linha de atuação diplomática que, na maior parte do período, manteve, porém, um considerável grau de coerência.

A década de 1990, cujo início praticamente coincidiu com a implosão do império soviético e com o desaparecimento da URSS, presenciou mudanças algo paradoxais na nossa política internacional. Com o fim da Guerra Fria, a fidelidade política ao bloco ocidental perdera sua razão de ser. Em ampla medida, ela foi, entretanto, substituída pela adesão do país ao pensamento econômico de Washington e, conseqüentemente, por uma nova percepção do papel do Estado na promoção do desenvolvimento econômico. A fidelidade político-ideológica cedeu, assim, lugar à afinidade econômico-doutrinária, e as duas constantes mencionadas no parágrafo anterior desapareceram da agenda diplomática brasileira como condicionantes autônomos - e às vezes conflitantes - de nossa atuação externa, convergindo na prática para uma ampla aproximação política e econômica com os Estados Unidos e "uma certa indefinição sobre o papel internacional do Brasil". ${ }^{1}$

* Embaixador aposentado (soutomaiorl@terra.com.br).

1 Souto Maior, Luiz A. P., "Desafios de uma Política Externa Assertiva”, Revista Brasileira de Política Internacional, Ano 46, no. 1, 2003. 
Em princípios deste século, um novo governo assumiu o poder com uma visão internacional distinta e uma plataforma de política externa muito mais assertiva do que aquela que prevalecera na década anterior. Tratava-se agora de "garantir uma presença soberana do Brasil no mundo"2 e de fazer da ação diplomática, "antes de tudo, um instrumento do desenvolvimento nacional"3. Esse ativismo voltado para o desenvolvimento econômico vinha também marcado por uma preocupação regionalista, que já não hesitava em comprometer-se com o fortalecimento institucional do Mercosul - que deve, "obviamente, dotar-se de uma política externa comum" - e com "a integração da América do Sul em seu conjunto." No âmbito sul-americano, a assertividade é, pois, temperada pela aceitação de uma institucionalidade forte, que inevitavelmente criaria limites à liberdade de atuação do país. Trata-se, pois, de uma atitude a um tempo ousada e cautelosa, que preconiza uma institucionalização necessariamente limitativa da nossa liberdade de atuação, mas não hesita, diferentemente do passado, em afirmar uma disposição de liderança regional que, no âmbito do Mercosul, deverá, entretanto, conformarse às normas das instituições que se pretende criar.

A nova assertividade da política externa brasileira projeta-se também para fora do âmbito continental, ao proclamar a intenção de Brasília de contribuir para a democratização das relações internacionais e estimular "os incipientes elementos de multipolaridade da vida internacional contemporânea”. Para tanto, caberia manter fortes vínculos bilaterais tanto com os grandes países desenvolvidos quanto com outros países em desenvolvimento de maior expressão geopolítica e econômica. Tal aproximação visaria não apenas a benefícios mútuos diretos, mas também à cooperação em organismos multilaterais, com vistas à consecução daqueles mencionados objetivos mais amplos de reforma da vida internacional. A criação do G-20, às vésperas da reunião ministerial da Organização Mundial de Comércio (OMC), em Cancun, e a do G-4, no âmbito da ONU, com vistas à reforma do Conselho de Segurança, no qual nosso país aspira a um assento permanente, ilustram a nova orientação da política externa brasileira.

Em suma, o Brasil deixou de apresentar-se apenas como membro ativo do grupo dos países em desenvolvimento para assumir uma posição de potência emergente ${ }^{4}$, em busca da situação a que se considera com direito na comunidade internacional.

2 Silva, Luiz Inácio Lula da, "Presença soberana no mundo", Carta Internacional, no. 114, ano X, agosto de 2002 , p. 9.

3 Silva, Luiz Inácio Lula da, Discurso de posse, texto publicado na Gazeta Mercantil, 2.1.2003, p. A-7.

${ }^{4}$ A expressão "potência emergente" é usada neste artigo para descrever a situação daqueles países em desenvolvimento cuja política aspira não apenas ao próprio progresso econômico, mas também, especificamente, a uma ampliação da sua projeção externa. 
O objetivo deste artigo não é, porém, às vésperas da próxima eleição presidencial, examinar a política externa do governo Lula ou a maneira como vem sendo executada. Trata-se aqui de fazer uma reflexão sobre em que medida a mudança das condições mundiais e nacionais justifica que, sem esquecermos a condição de país em desenvolvimento que ainda é a nossa, assumamos, no nosso continente e no mundo, uma posição de potência emergente, independentemente de quem ou de que partidos vençam as eleições de 2006.

\section{Uma certa perplexidade}

A dificuldade em precisar o que caracteriza a ordem mundial desde meados do século passado criou a tendência a rotular cada fase em relação ao passado mais recente - mundo pós-Segunda Guerra Mundial, pós-Guerra Fria, pósmoderno - ou de acordo com a divisão internacional de poder, real ou percebida - mundo unipolar, bipolar... Seguindo tal tendência, seria igualmente válido falarmos de um mundo pós-bomba atômica, já que foi o desenvolvimento deste artefato bélico e a demonstração prática de seu poder destrutivo sobre os infelizes habitantes de Hiroshima e Nagasaki que determinou uma das principais características políticas do período considerado - a ausência de enfrentamento militar entre as grandes potências.

A certeza de que uma guerra entre potências nucleares resultaria, para ambos os contendores, numa destruição tamanha que seria difícil falar em vencidos ou vencedores levou à eliminação do choque bélico como forma extrema de solução de diferenças entre elas. Pela sua própria natureza, não se poderia aplicar a um conflito militar com armas atômicas a noção de Clausewitz de que a guerra é a continuação da política por outros meios. A expressão Guerra Fria descreve sinteticamente tal estado de coisas: uma situação na qual duas superpotências viviam em constante enfrentamento político, mas sempre com o cuidado de evitar situaçóes que tornassem um choque militar inevitável ou altamente provável. A crise de Berlim, a atitude de Washington em relação aos seus aliados quando do apoio militar anglo-francês a Israel, em 56, ou a retirada dos mísseis soviéticos de Cuba, no começo da década de 1960, são exemplos de casos em que se evidenciou esse cuidado de evitar o abismo. Entre Estados, a força militar das grandes potências passaria a ser usada apenas contra países menores, desprovidos de armamento nuclear.

A assinatura da Carta das Nações Unidas consagrou juridicamente tal situação ao reservar para o Conselho de Segurança o monopólio do uso internacional da força e atribuir o direito de veto a seus cinco membros permanentes - que eram ou logo se tornariam potências nucleares "legais". Daí em diante, o uso internacional da força militar só seria juridicamente válido em casos de legítima defesa ou quando tivesse a aquiescência consensual das potências nucleares. 
Para a comunidade internacional, tal estado de coisas criava, porém, um dilema. Aos Cinco Grandes, interessava - e interessa - manter o oligopólio do poder nuclear. Para isso é indispensável evitar que outros Estados venham a dispor de armas atômicas e dos meios de lança-las ou, para usar o jargão que se tornou corriqueiro, é indispensável impedir a "proliferação" de tais armas. Aos demais, entretanto, interessa, conforme o caso, a obtenção de armamento nuclear próprio e dos vetores necessários ao seu lançamento sobre os alvos escolhidos ou a eliminação total desse tipo de armas, inclusive das ogivas e mísseis em mãos dos Cinco Grandes. Esta última alternativa tem-se revelado, porém, inexequível. Na prática, o que parece estar ocorrendo é o gradual desgaste do objetivo de "não-proliferação" e o surgimento de quatro categorias de Estados: a) aqueles que possuem "legalmente" armas nucleares; b) aqueles que não estão ligados ao Tratado de Não-Proliferação, mas são considerados pelos grandes como suficientemente úteis ou confiáveis (Índia, Israel, Paquistão) para que seu arsenal atômico seja de facto aceito; c) aqueles que, embora pouco confiáveis, são considerados demasiado perigosos para serem facilmente coagidos a "desnuclearizar-se" (Coréia do Norte e, no futuro, talvez o Irã); d) os nãonucleares. Felizmente, parece relativamente pequeno o número de países que não só sentem a necessidade como têm as condições econômicas, técnicas e políticas de adquirir armamento nuclear e os respectivos meios de lançamento. Por outro lado, torna-se crescente o risco de que algum artefato dessa natureza - mesmo rudimentar, como as chamadas bombas sujas - caia em mãos de grupos terroristas.

Paralelamente, o desenvolvimento da tecnologia militar convencional alcançou um nível em que é possível a um país mais avançado, sem sofrer quaisquer baixas, infligir danos insuportáveis a outro que não disponha dos mesmos recursos. Os bombardeios da Sérvia pelas forças da Otan, que culminaram com a entrega de Slobodan Mlosevic a um tribunal internacional, ilustram bem tal situação. É claro, entretanto, que esse tipo de tecnologia bélica só está ao alcance de países que dispõem de uma base econômica e técnica suficientemente sólida para sustentá-la.

Em suma, mudaram a natureza do poder militar e, conseqüentemente, as posições políticas de nações que se tinham historicamente habituado a ver nos conflitos bélicos a forma extrema de acerto das suas controvérsias. Hoje, potências nucleares não se guerreiam porque isso equivaleria a um pacto de suicídio conjunto. Em princípio, as armas atômicas são, pois, mantidas e desenvolvidas, não para serem usadas, mas para dissuadir outras potências nucleares de usarem as delas. Por sua vez, as potências menores - que sabem que só em circunstâncias absolutamente extremas seriam alvo de um ataque nuclear - já não têm o recurso de desenvolver uma força militar convencional capaz de infligir perdas inaceitáveis a um eventual agressor mais poderoso, que utilize armas também convencionais de última geração. Tal política de defesa 
seria inútil contra um inimigo capaz de causar danos incomensuráveis ao país mais débil sem expor suas próprias forças em enfrentamentos diretos.

Um mundo em que as grandes potências militares deixaram de fazer a guerra umas as outras, mas onde, em conjunto ou isoladamente, podem, praticamente sem sofrer perdas humanas, levar a destruição a países mais fracos pareceria o terreno ideal para o exercício da tirania desenfreada dos mais poderosos. No entanto, embora subsista, como sempre, a prevalência dos mais fortes, a dominação política aberta tornou-se menos freqüente, tendo praticamente desaparecido o colonialismo tradicional. A preeminência dos poderosos passou a perseguir objetivos distintos e a assumir formas bem mais sutis.

Por um lado, valores como a auto-determinação dos povos e o respeito aos direitos humanos tornaram-se crescentemente aceitos internacionalmente e, conseqüentemente, sua violação tende a ser rejeitada pela opinião interna dos grandes Estados, exceto em situaçóes percebidas como de ameaça à própria segurança. Assim, excluídos os casos de nacionalismo exaltado ou de fundamentalismo religioso, os povos dos países mais avançados - e poderosos - parecem mais interessados na defesa de seu padrão de vida e no respeito aos seus próprios valores do que na glória de conquistas militares. Isso é particularmente verdadeiro nas sociedades democráticas, como bem ilustra a reação da opinião pública americana em relação ao governo Bush à medida em que se foram revelando a falácia dos motivos alegados para o ataque ao Iraque e a dificuldade em atingir os objetivos declarados. Frente a esse conjunto de circunstâncias técnicas e políticas, parece válida a ponderação de que "a guerra não se tornou impossível, mas é muito menos aceitável hoje do que era há um ou mesmo há meio século." 5

Num mundo em que tradicionalmente a noção de poder nacional tendia a ser equiparada à de poderio militar, todas essas mudanças suscitam uma reflexão sobre os atuais condicionantes do poder nacional. Parece evidente que o poder econômico se tornou muito mais importante do que no passado, não só porque é o alicerce indispensável à manutenção de qualquer máquina bélica moderna, mas também porque mesmo as economias mais poderosas enfrentam um problema de opções. Isso ficou patente já nas primeiras décadas da Guerra Fria, quando Washington optou por, ao mesmo tempo, manter a liderança político-militar do bloco ocidental e promover a recuperação econômica dos seus principais aliados, essencialmente a Europa Ocidental e o Japão. A conseqüência mais evidente foi a erosão relativa da preeminência econômica dos Estados Unidos, com o resultante fim da conversibilidade do dólar em ouro, no começo da década de 1970, a desvalorização da moeda americana e, dois anos depois, o colapso formal do sistema de paridades fixas estabelecido

\footnotetext{
${ }^{5}$ Nye Jr., Joseph S. O Paradoxo do Poder Americano, Editora UNESP, 2002, p.33.
} 
em Bretton Woods. Já na década de 1990, o mundo assistiu à Guerra do Golfo, um empreendimento político-militar liderado pelos Estados Unidos, levado a cabo com instrumentos bélicos dominantemente americanos, mas para cujos gastos financeiros Washington arcou com uma percentagem bastante modesta. Em suma, a Europa e o Japão optaram pela própria prosperidade, deixando aos EUA a preeminência estratégica e a principal responsabilidade pela segurança do Ocidente, mesmo ao custo político de financiarem a liderança americana sobre eles mesmos.

Tudo isso nos deixa sem uma resposta clara sobre o que se entende por poder e quais os seus fundamentos no âmbito internacional, algo relevante no contexto da presente reflexão. Para facilidade de análise, poderíamos partir da conceituação simplificada proposta por Joseph Nye, para quem ele seria "a capacidade de obter os resultados desejados e, se necessário, mudar o comportamento dos outros para obtê-los." "Tratar-se-ia, portanto, não apenas da capacidade de auto-realização do país (seu desenvolvimento econômico e social, por exemplo), mas também da sua capacidade de influenciar o comportamento dos demais, de modo a criar um ambiente favorável à consecução dos próprios objetivos.

Neste último sentido, ele tem sido tradicionalmente equiparado ao peso militar e/ou econômico relativo de cada país, no âmbito regional ou mundial. Ambos representam o que tem sido denominado de poder duro, a capacidade de pressionar o mais fraco para leva-lo curvar-se ao desejo do mais forte. Também existe, entretanto, o chamado poder brando, que consiste na capacidade de liderar sobretudo pelo exemplo e pela persuasão. Isto implica em que os liderados percebam os objetivos preconizados pelo líder como conducentes ao bem comum, pelo menos em suas linhas gerais. Essencialmente, foi esse o tipo de liderança exercido pelos Estados Unidos sobre seus aliados da Otan durante a Guerra Fria. Apesar de divergências tópicas, prevalecia o sentido de parceria para a consecução de objetivos maiores de segurança frente à ameaça soviética.

Neste começo de século XXI, terminada a rivalidade entre as duas superpotências, que condicionara a ordem mundial entre o término da Segunda Guerra Mundial e o fim da década de 1980, reina uma certa perplexidade quanto ao que seja a ordem atual e ao papel que nela cabe tanto aos protagonistas tradicionais como aos países que foram assumindo o papel de potências emergentes, entre os quais o Brasil.

\section{Atores em busca de um papel}

Durante mais de quatro décadas a atenção da comunidade internacional esteve voltada dominantemente para aquela rivalidade, que não só condicionava

\footnotetext{
${ }^{6}$ Nye Jr, Joseph S. Op. cit., p. 30.
} 
a segurança mundial, mas também oferecia uma opção política e ideológica aos países menos engajados, geralmente do terceiro mundo. Isto não significa que não estivessem ocorrendo desenvolvimentos de monta não diretamente relacionados com tal rivalidade. Talvez uma das mais interessantes tenha sido o crescimento do peso econômico relativo daqueles a que hoje se tornou usual chamar de países emergentes. Assim, já num ensaio publicado em $98^{7}$, Bowman Cutter refere-se a um grupo que chama de "new Big 7" (China, Índia, Indonésia, Brasil, Coréia do Sul, Tailândia e Rússia), os quais, na sua estimativa, responderão, nos vinte anos seguintes, por mais de metade do crescimento mundial, enquanto os atuais "7 Grandes" serão responsáveis por menos de um quarto. E mais. Tomado em conjunto, o PIB daqueles novos Sete, segundo o mesmo autor, será, ao fim daquelas citadas duas décadas, maior do que o dos atuais. Evidentemente, não se pode atribuir uma grande precisão a tais extrapolações, mas o fato concreto é que, em 2003, segundo comparação publicada por The Economist com base na paridade do poder de compra das moedas, das dez maiores economias mundiais (Estados Unidos, China, Japão, Índia, Alemanha, França, Grã-Bretanha, Itália, Brasil e Rússia), quatro eram países em desenvolvimento ${ }^{8}$. Num texto mais recente ${ }^{9}$, a mesma revista assinala que, em 2005, as "economias emergentes produziram pouco mais da metade do produto mundial medido pela paridade do poder aquisitivo das moedas" e também "responderam por mais da metade do aumento do PIB global em termos de dólares correntes". No mesmo sentido, caberia recordar uma apreciação ainda mais recente de John Major, ex-primeiro-ministro do Reino Unido e hoje conselheiro do Crédit Suisse, para quem, "nos últimos sessenta anos, a economia mundial cresceu puxada por três motores: EUA, Japão e União Européia. Em breve os motores serão seis: os três de antes mais China, Sudeste Asiático e Índia. E talvez alguns outros países emergentes, como o Brasil. Isso significa que já não teremos mais uma nação tão dominante. Os EUA continuarão os maiores, e são infinitamente mais poderosos em termos militares, mas serão os primeiros entre pares." 10 Em sentido semelhante, a expressão Bric, referindo-se às maiores economias emergentes - Brasil, Rússia, Índia e China -, tornou-se corriqueira, e os quatro, com suas potencialidades e mazelas, passaram a ocupar crescentemente a atenção dos países da OCDE. ${ }^{11}$

\footnotetext{
7 Cutter, W. Bowman, "A New International Economic Order?" in Robert Hutchings (ed.), At the End of the American Century, The Johns Hopkins University Press, Baltimore, 1998.

8 "A Survey of the World Economy - The dragon and the eagle", p. 7, The Economist, 2-8.10.2004.

9 The Economist, 21.1.2006, p. 10.

${ }^{10}$ Major, John, entrevista publicada no jornal Valor Econômico, de 21.3.2006, p. A14.

${ }^{11}$ Ver, por exemplo, notícia sobre reunião da OCDE, em maio último, em que se assinalou que os BRIC, liderados no caso pela China, teriam aumentado de $18 \%$ para $27 \%$ sua participação no produto mundial, entre 90 e 2005. Nos últimos cinco anos, os quatro teriam assim contribuído quase tanto quanto os trinta países da OCDE para o crescimento do produto global. Valor, 25.5.2006, p. A9.
} 
As implicações de tais desenvolvimentos não eram, porém, imediatas e, dada a polarização de forças prevalecente durante a Guerra Fria, a atenção dos estadistas da época tampouco tendia a deter-se na relevância que eles poderiam ter a mais longo prazo. Assim, foi preciso que desaparecesse o bipolarismo da ordem mundial para que se colocasse a questão de como se deveria estruturar uma comunidade internacional tão diferente da existente ao término da Segunda Guerra Mundial.

Inicialmente, Washington tomou uma iniciativa retórica, de sabor wilsoniano, em favor do estabelecimento de uma "nova parceria de naçōes", baseada no respeito ao direito internacional e numa divisão eqüitativa de responsabilidades entre os Estados ${ }^{12}$. Logo se tornou evidente, porém, que tal parceria - e o genuíno multilateralismo que ela implicaria - teriam de ceder o passo às realidades do poder e ao pragmatismo da política internacional. Continuavam, portanto, sem resposta as questões básicas suscitadas pelas mudanças ocorridas na ordem mundial que se tratara de estabelecer mais de quatro décadas antes. Em que consistia o poder internacional nas novas circunstâncias do mundo? Quem o detinha? De que maneiras seus detentores podiam utilizá-lo e com que conseqüências para a comunidade internacional? Em suma, que ordem mundial substituiria o bipolarismo defunto?

Para uns, como Fukuyama, o fim do império soviético e o fracasso da ideologia por ele encarnada levara ao fim da história; para outros, como Huntington, iniciava-se um período de choque entre civilizações; para outros ainda, como Joseph Nye, o mundo vive uma realidade extremamente complexa, que não permite esquematizações simplistas. Dentro dos objetivos já mencionados deste artigo, não cabe examinar as diferentes teses sobre a atual ordem mundial, mas tão somente refletir sobre a posição do Brasil num mundo em transição.

\section{Hegemonia em cheque?}

Depois de várias décadas, em que duas superpotências disputaram a hegemonia mundial, criando na prática uma ordem internacional bipolar, é natural que, com a desaparição de uma delas, a outra se considere o centro da nova ordem e passe a atuar no sentido de obter que os demais a reconheçam como tal. Por outro lado, não é menos compreensível que muitos paises que tinham seguido sem maiores questionamentos a liderança de Washington, vista como necessária à segurança do Ocidente face à ameaça soviética, passem, desaparecido este perigo, a exibir maior desenvoltura em suas políticas externas. Essa nova atitude tem-se manifestado, em diferentes graus, tanto entre grandes

\footnotetext{
12 Discurso do presidente George Bush perante a Assembléia Geral das Nações Unidas, em 1.10.90.
} 
potências tradicionais como entre países emergentes que, no período considerado, haviam adquirido um peso especifico de que absolutamente não dispunham em meados do século passado. Assim, pode-se dizer que a ordem mundial formalmente vigente, tal como refletida em instrumentos como a Carta das Nações Unidas e o Tratado de Não-Proliferação, já não satisfaz inteiramente a quem quer que seja, mas tampouco existe qualquer indício de consenso sobre como torná-la mais consentânea com a realidade atual.

Para Joseph Nye, o jogo internacional de poder pode ser hoje comparado a uma complexa partida tridimensional de xadrez. No primeiro tabuleiro, onde está em causa o poder militar, é possível falar em um mundo unipolar, dada a enorme superioridade quantitativa e tecnológica dos Estados Unidos, capaz de enfrentar com êxito qualquer inimigo potencial ou aliança provável de adversários. No segundo, onde se disputa o poder econômico, já não existe uma potência igualmente avassaladora, prevalecendo, assim, uma situação de multipolaridade. Paralelamente, num terceiro tabuleiro, desenvolve-se um número crescente de atividades transnacionais legais e ilegais, que vão desde a atuação de grandes corporações multinacionais até o terrorismo, passando pelo narcotráfico e a lavagem de dinheiro. Embora de nível infra-estatal, sua relevância para a política internacional é inegável. Nesse terceiro tabuleiro, seria fútil, entretanto, falar de unipolarismo, multipolarismo ou qualquer outra forma razoavelmente estável de distribuição internacional de poder.

Para atuar dentro desse quadro complexo, os atores disporiam, em diferentes graus, de um poder duro, essencialmente militar ou econômico, que possibilitaria o exercício de pressões diretas do mais forte sobre o mais fraco, mas haveria também - e não menos relevante - um poder brando, que se exerceria sobretudo pela cooperação e pelo exemplo. A eficácia relativa de cada uma dessas formas de poder dependeria do objetivo que se tenha em mira. Assim, a relevância do poder militar para a política externa não desapareceu, porém sua importância diminuiu, não apenas pelas razões já apontadas acima, mas também porque um número crescente de problemas exige um grau de cooperação internacional inalcançável apenas pelo uso do poder duro.

Em tal contexto, o maior ou menor êxito da atuação internacional dos Estados Unidos, como maior potência mundial, muito dependerá da sua habilidade em utilizar os enormes recursos ao seu dispor. Não apenas - ou sequer dominantemente - os militares, mas também o seu peso econômico e os aspectos positivos do seu sistema político-social, bem como sua capacidade de difusão cultural. Em outras palavras, muito dependerá de como Washington administrará a delicada passagem da hegemonia para a liderança, quando parafraseando John Lewis Gaddis ao referir-se ao poder brando - se tratará de conseguir que outros queiram o que o líder quer e não apenas que façam o que ele deseja que seja feito. 


\section{Regionalismo e afirmação nacional}

Por definição, um país em desenvolvimento que aspira a uma maior projeção externa - seja em âmbito regional, seja internacional - não tem os meios de conseguir tal objetivo sem o concurso de outros. Tal circunstância é um dos fatores que têm levado à multiplicação dos arranjos econômicos regionais. Eles podem contribuir para aumentar, ainda que em diferentes graus, o peso específico dos participantes individuais. Podem também ser utilizados para inibir uma potência de dentro ou de fora da área de exercer uma influência considerada excessiva em assuntos da região. A primeira reunião de Cúpula da Ásia Oriental, realizada na Malásia, em dezembro do ano passado, é um bom exemplo deste último caso. Nela estiveram presentes os dez membros da Associação das Naçôes do Sudeste da Ásia (Asean, na sigla em inglês), a China, o Japão e a Coréia do Sul. Também foram convidados a Austrália, a Índia e a Nova Zelândia, mas não os Estados Unidos. Aparentemente, a maioria concordou em evitar uma presença americana que poderia perturbar as bases de uma "comunidade da Ásia oriental" dotada de "valores comuns" e de uma "identidade própria". ${ }^{13}$ Dados os laços políticos entre os EUA, e alguns dos países presentes, não se poderia falar de hostilidade em relação a Washington, mas de um aparente desejo de limitar uma intrusão considerada potencial ou atualmente excessiva, pelo menos por alguns países da região.

A situação no nosso continente - onde o espírito regionalista tem assumido diferentes formas - apresenta alguma analogia com a mencionada problemática asiática. Em 1823, ao enviar sua famosa mensagem ao Congresso americano, o presidente James Monroe assumiu unilateralmente a posição de patrono das Américas. Surgia assim o pan-americanismo, uma forma de regionalismo paternalista que, na época, oferecia vantagens circunstanciais àqueles países do continente que ainda lutavam por afirmar sua independência recente em relação às metrópoles européias. Evidentemente, faltava-lhe, porém, o elemento de consenso ou sequer de consulta. Em suma, era uma iniciativa de política externa de Washington - que por sua vez se escudava no apoio, tido como certo, embora não declarado, da esquadra britânica - que afetava todo o continente.

Já no fim do século, quando da I Conferência Internacional Americana (1889-1890), os Estados Unidos, fortes da sua posição de maior potência das Américas e desejosos de eliminar a preeminência comercial das economias européias na região, lançou a idéia de uma união aduaneira de âmbito continental. Olhando retrospectivamente, é interessante recordar que, naquela conferência, o grande adversário dessa precursora da Alca foi o delegado argentino Roque Saens Peña.

13 Pomonti, Jean-Claude, "Redistribution des cartes en Asie", Le Monde Diplomatique, Dezembro 2005, p. 10. 
O projeto integracionista não prosperou, mas foram lançadas as bases formais de um pan-americanismo dominantemente econômico, com a criação de um Bureau Internacional das Repúblicas da América, "destinado a reunir e publicar as informações relativas ao comércio, aos produtos, às leis e as tarifas dos países que o compõem". Pouco mais de meio século depois, já no ambiente internacional da Guerra Fria, ele assumiria sua institucionalidade política atual, com o estabelecimento da Organização dos Estados Americanos (OEA) e a assinatura do Tratado Interamericano de Assistência Recíproca (Tiar).

A essa visão monroísta, que via no Hemisfério Ocidental uma vasta área de influência dos EUA, veio a contrapor-se uma percepção bolivariana, que buscava aproximar as nações americanas de colonização espanhola. $\mathrm{Na}$ visão de Bolívar, ficariam, porém, de fora tanto os Estados Unidos, anglo-saxônico e dominador, como o Brasil, lusitano e imperial. Só muito gradualmente, com a solução dos problemas de fronteiras com os nossos vizinhos, a noção das afinidades do subdesenvolvimento e dos benefícios potenciais da integração econômica entre os países pobres do continente, essa visão bolivariana foi cedendo lugar a uma percepção latino-americanista, que nunca chegou, entretanto, a adquirir significação efetiva, econômica ou política. Sua expressão institucional mais abrangente é o Sistema Econômico Latino-Americano (Sela), que pouco tem representado como elemento aglutinador dos países da América Latina. Da mesma forma, as iniciativas tendentes a fomentar especificamente a integração econômica dos países latino-americanos - o Tratado de Montevidéu I (60), que criou a Alalc, e o Tratado de Montevidéu II (80), que estabeleceu a Aladi - tampouco contribuíram significativamente para dar ao conjunto dos países latinos do continente uma identidade política própria. Nem sequer se aproximaram da meta declarada de um mercado comum dos Estados-parte.

O escasso êxito desses esforços para criar uma personalidade latinoamericana não impediu - possivelmente terá mesmo estimulado - iniciativas mais limitadas, de âmbito sub-regional, com vistas a objetivos menos abrangentes. Assim, em 69, Brasil, Argentina, Bolívia, Paraguai e Uruguai firmaram, em Brasília, o Tratado da Bacia do Prata, para "promover o desenvolvimento harmônico e a integração física da Bacia do Prata e de suas áreas de influência direta e ponderável." ${ }^{14}$ Em 78, também em Brasília, Brasil, Bolívia, Colômbia, Equador, Guiana, Peru, Suriname e Venezuela firmaram o Tratado de Cooperação Amazônica, pelo qual se comprometiam a "realizar esforços e açóes conjuntas para promover o desenvolvimento harmônico de seus respectivos territórios amazônicos". ${ }^{15}$ Os objetivos dos dois instrumentos têm evidentes pontos em comum, e o fato de participar simultaneamente de ambos colocou o Brasil como traço de união entre duas redes de cooperação

14 Tratado da Bacia do Prata, art. 1.

15 Tratado de Cooperação Amazônica, art. 1. 
sub-regional que, tomadas em conjunto, cobrem praticamente toda a América do Sul. Em certo sentido, pode-se dizer, portanto, que, ao promover a conclusão do instrumento amazônico, o Brasil estava antecipando outra forma de regionalismo continental - o sul-americanismo -, que só viria a explicitar-se bem mais tarde. Com a iniciativa da Área de Livre Comércio Sul-Americana (Alcsa) e sobretudo com a realização da I Reunião de Cúpula Sul-Americana, o Brasil lançaria ostensivamente no continente as bases formais de um novo movimento regional, presumivelmente mais consentâneo com a sua efetiva capacidade de influência na área.

Escrevendo em maio de 2000 sobre a reunião de cúpula dos países da América do Sul, que se realizaria meses depois, o embaixador Luís Felipe Lampreia, então nosso ministro das Relações Exteriores, ressaltou a especificidade da América do Sul, pelo que teriam sido deixados de fora a América Central e o Caribe, "vinculados de forma mais próxima e direta à América do Norte, em particular aos Estados Unidos"16. O Brasil marcava assim, ostensivamente, uma clara distância em relação ao pan-americanismo e qualificava o seu latino-americanismo, dando prioridade a "um projeto pragmático de organização do espaço sul-americano". ${ }^{17}$

Esta tem sido também a orientação do governo atual, aparentemente disposto a promover a união dos países sul-americanos a partir do núcleo representado por um Mercosul que, na visão de Brasília, deveria ser aprofundado e consolidado, a ponto de dotar-se de uma política externa comum. Tal projeto, se bem sucedido, certamente aumentaria o peso internacional de cada um dos seus integrantes e, no caso do Brasil, nos ofereceria uma base regional de tais amplitude e solidez que muito facilitaria a consecução do objetivo de levar avante uma política externa de potência emergente. Resta saber se é factível.

Dos esquemas regionais ou sub-regionais de que o Brasil faz parte, o Mercosul é aquele que - apesar de suas limitações - apresenta os elementos institucionais e de coesão geográfica que, em tese, mais o habilitariam a tornarse o cerne de uma organização sul-americana - política e econômica - mais abrangente. A experiência dos 15 anos decorridos desde a assinatura do Tratado de Assunção deixa claro, entretanto, que não existe entre os quatro países signatários - Brasil, Argentina, Paraguai e Uruguai - e os dois associados Bolívia e Chile - a vontade coletiva de criar um mercado comum, muito menos um bloco capaz de atuar solidariamente na área internacional - econômica e política. Esta seria a razão profunda de os compromissos de 91, assumidos para serem cumpridos até 31 de dezembro de 94, permanecerem até hoje em grande parte letra morta ${ }^{18}$ : o mercado comum não é mais do que uma pseudo-

\footnotetext{
${ }^{16}$ Lampreia, Luís Felipe, "Cúpula da América do Sul”, Carta Internacional, no. 87, ano VIII, maio de 2000.

17 Lampreia, Luís Felipe, Op. Cit.

18 V. Tratado de Assunção, art. 1.
} 
união aduaneira, com uma tarifa externa comum cheia de exceçôes; a coordenação de políticas macroeconômicas e setoriais resta por fazer; a harmonização de legislações internas tampouco prosperou; divergências entre os Estados-parte transformam-se em problemas políticos pela falta de mecanismos institucionais para resolvê-las. Mesmo o grande feito do Mercosul, que foi a expansão do comércio entre os Estados-parte, parece ter entrado numa fase de estagnação ou de relativo declínio, na medida em que as vendas para os parceiros da área têm representado, nos últimos anos, uma percentagem declinante das exportações totais de cada país. Em 98, o Brasil exportou para o Mercosul 17,4\% de suas vendas externas de bens, enquanto em 2005 tal percentagem não excedeu os 9,9\%; na Argentina, a parcela das exportaçóes totais que se destinava aos parceiros da área era de 16,5\% em 91, subiu para $36,5 \%$ em 97, mas, em 2005, não excedeu 19,2\%; no caso do Uruguai, as percentagens correspondentes foram de 35\% em 91, de 42,7\% em 2001 e de apenas 23,5\% em 2005; no Paraguai, as exportaçōes intrazona, que atingiram $63,4 \%$ do total em 2001, caíram para 54\% em $2005 .{ }^{19}$

\section{O Brasil e o regionalismo continental}

Para o Brasil - que se percebe como uma potência emergente e é crescentemente visto como tal internacionalmente - o quadro acima esboçado coloca sérias questóes de política regional e internacional.

Simplificadamente, pode-se dizer que a idéia-chave subjacente à nossa atual política regional é a construção de uma base subcontinental tão ampla e sólida quanto possível, de modo a firmar a liderança brasileira na América do Sul, o que deveria facilitar, no âmbito mundial, o exercício de uma política de potência emergente. Ao adotarmos abertamente tal linha de conduta, afastamonos da prática tradicional brasileira de negar qualquer aspiração de liderança no subcontinente e aceitamos o risco de acirrar rivalidades e ressentimentos latentes em relação ao Brasil. Exemplificativamente, as resistências regionais a nossa aspiração a um assento permanente no Conselho de Segurança da ONU e o escasso apoio à candidatura de um brasileiro à direção da Organização Mundial de Comércio são sintomáticas de tal situação.

O problema não se restringe, entretanto, a rivalidades por motivos de projeção externa. Chega ao campo das divergências de interesses - reais ou percebidas - e do surgimento de lideranças sub-regionais conflitantes com a nossa. A situação é ilustrada pelo rumo que tomou a aproximação entre Bolívia, Cuba e Venezuela e, particularmente, pelo discurso do governo Evo Morales, que oscila entre a animosidade grosseira em relação ao nosso país e o desejo declarado de, nas palavras do vice-presidente, "ser o sócio mais importante de

19 Valor Econômico, 28.3.2006, p. A2. 
abastecimento energético" (do Brasil) ${ }^{20}$. A dubiedade da retórica boliviana reflete a ambigüidade da posição daquele país, mas também assinala as possibilidades que nos são abertas pelo peso específico do Brasil, não só em relação à Bolívia, mas no conjunto da América do Sul. Em entrevista coletiva em Viena ${ }^{21}$, o presidente Morales deixou clara sua hostilidade á Petrobras e a outras petroleiras, que operariam em seu país com contratos "ilegais e inconstitucionais". Manifestou também sua aparente preferência por países como Japão, Cuba, Venezuela e alguns europeus não identificados, "que ajudam sem pré-condições", em contraste com o Brasil, com quem "falamos bastante e não concretizamos absolutamente nada", e que, no passado, obteve "o Acre em troca de um cavalo". Por outro lado, o vice-presidente Álvaro Garcia Linera, na entrevista acima citada, assinalava que os acordos energéticos com a Venezuela, "país irmão",(...) "são investimentos de US\$70 milhões, US $\$ 80$ milhōes. E com a Petrobras temos US $\$ 1,5$ bilhão em acordos." Em suma, a leitura do discurso político boliviano deixa a impressão de que coexistem em La Paz uma simpatia político-ideológica por Cuba e Venezuela, mas também o reconhecimento pragmático de que o Brasil é um parceiro mais relevante, e que, portanto, caberia conservá-lo como tal.

As divergências na área andina não têm, porém, repercussões apenas sobre as aspirações brasileiras de liderança no nosso subcontinente. Elas afetam sobretudo a estabilidade da Comunidade Andina de Nações (CAN), na medida em que Colômbia e Peru tendem a firmar instrumentos bilaterais de comércio com os EUA, enquanto Venezuela e Bolívia ameaçam deixar a CAN por se oporem a eles. Ao mesmo tempo, o Equador, que também negocia um acordo de comércio com Washington, decidiu rescindir os contratos com a companhia americana Occidental, o que teria levado os Estados Unidos a suspenderem as negociações.

Paralelamente a esse bosquejo de algumas das complexidades da atual situação na América do Sul, o próprio Mercosul, visto por Brasília como núcleo de uma integração mais ampla do nosso subcontinente, parece ter hoje um futuro incerto. Por um lado, a falta de instituiçôes adequadas torna politicamente sensíveis controvérsias - como as freqüentes desavenças entre o Brasil e a Argentina ligadas ao protecionismo desta última - que, num organismo mais estruturado, deveriam ser resolvidas por procedimentos ordinários de solução de divergências. Por outro, a assimetria entre os dois sócios maiores e os dois menores tendem, na ausência de mecanismos compensatórios eficazes, a alimentar insatisfações de parte destes últimos. É o que ocorre no momento, quando o presidente do Uruguai manifesta a intenção de fortalecer seus vínculos comerciais com os Estados Unidos e deixa claro que o Mercosul, tal como

${ }^{20}$ Entrevista do vice-presidente Alvaro Garcia Linera, Valor Econômico, 15.5.2006, p.A4.

21 Valor Econômico, 12, 13 e 14 de maio de 2006, p. A4. 
existe, tem pouco interesse para o seu país. Nada disso prenuncia o fim próximo do projeto que se denominou, algo prematuramente, Mercado Comum do Sul. Significa, porém, que os países que o integram enfrentam um dilema: rever em profundidade seus objetivos e instituições - certamente uma tarefa árdua e de longo prazo - ou deixar que definhe rumo a uma relativa irrelevância, sobretudo em negociações com terceiros.

$\mathrm{O}$ quadro geral de divergências de interesses e percepções acima esboçado é, por si só, complexo bastante para tornar extremamente problemático o projeto do atual governo brasileiro de promover a integração da América do Sul. As dificuldades de origem dominantemente sul-americanas tinham sido multiplicadas, porém, pela proposta americana de uma área hemisférica de livre comércio, que, à primeira vista, parecia abrir aos países latino-americanos, em base preferencial, o maior mercado nacional do planeta. A iniciativa de Washington - formalmente aceita pelo conjunto dos países latino-americanos, menos Cuba, na I Cúpula das Américas, em 94 - até hoje não conseguiu concretizar-se. Parece ter mesmo perdido muito da sua relevância na política latino-americana dos EUA, que, sem abandonarem declaradamente a idéia da Alca, passaram a negociar acordos com diferentes países ou grupos de países da região. O que aparentemente subsiste, pois, em Washington é a idéia de atrelar aos Estados Unidos as economias emergentes da América Latina, em conjunto ou separadamente. $\mathrm{Na}$ medida em que tal projeto consiga congregar todos ou a grande maioria dos países da região, suas implicaçóes políticas parecem evidentes.

O que nunca ficou claro, entretanto, pelo menos para a opinião pública, foi como se conciliariam - ou como interagiriam - o sul-americanismo de Brasília e o pan-americanismo de Washington, sobretudo a partir do momento em que os EUA reconheceram que, apesar da sua liderança no continente, as peculiaridades nacionais ou sub-regionais latino-americanas tornavam problemática a construção de uma área hemisférica de livre comércio. Sem abandonarem a idéia inicial, passaram, portanto, a concluir acordos de âmbito mais limitado. Ao fazê-lo, puseram em cheque a coesão do próprio Mercosul e, com mais forte razão, qualquer projeto integracionista que abrangesse toda a América do Sul.

De maneira mais crua, poder-se-ia perguntar como o Brasil, que com os outros três co-signatários do Tratado de Assunção não conseguiu que se cumprissem sequer os compromissos assumidos naquele instrumento, vai levar os quatro a adotarem uma política externa comum e - ainda mais difícil congregar o conjunto da América do Sul em torno de objetivos aceitos por todo o subcontinente?

Provavelmente não o conseguirá, pelo menos no futuro previsível. Se este for o caso, como me parece, em que medida tal situação comprometerá a política externa do atual governo e, sobretudo, a idéia mais ampla de uma política externa de potência emergente? 
É normal que um país com as dimensões territorial, demográfica e econômica alcançadas pelo Brasil aspire a ter, na cena internacional, um papel mais marcante do que aquele que lhe tem cabido até agora. Dentro da mesma ordem de idéias, é ainda mais natural que, pelo seu peso relativo, se perceba na posição de primus inter pares na América do Sul. Em última análise, tal situação objetiva não é contestada sequer pelos nossos vizinhos, embora, como já assinalado acima, isso seja freqüentemente motivo de preocupação e ressentimento. Em tais circunstâncias, arrogar-se ostensivamente uma posição de liderança sul-americana será sempre contraproducente, ainda que procurar discretamente exerce-la na prática, não necessariamente o seja. Trata-se, portanto, de ter uma noção muito clara daquilo que uma ainda hipotética liderança regional brasileira poderia ser e - ainda mais importante - daquilo que não deveria ser nem parecer ser.

Tudo o que foi dito até aqui parece deixar clara a inviabilidade do estabelecimento de um conjunto de normas e instituiçôes capazes de orientar, num sentido comum e solidário, a atuação internacional dos países sulamericanos em seu conjunto ou sequer a daqueles que integram o Mercosul. Esta última hipótese - aparentemente acalentada pelo atual governo, que deseja uma política externa comum aos signatários do Tratado de Assunção - já representaria um enorme passo, mas parece inviável dentro de qualquer horizonte cronológico relevante.

Inegavelmente, um Mercado Comum do Sul cuja realidade correspondesse a sua ambiciosa denominação aumentaria consideravelmente a projeção econômica internacional de cada um dos seus integrantes, com reflexos no campo político. Isso seria verdadeiro mesmo se, à integração econômica, não fosse possível acrescentar uma política externa comum, como já mencionado. Qualquer dessas hipóteses envolve, porém, duas pré-condições. A primeira é um entendimento muito mais profundo com a Argentina - no político e no econômico - do que tudo quanto, até agora, tem sido possível estabelecer de forma estável. Sem ele, porém, o Mercosul tenderá a perder muito da sua relevância, como aparentemente já está acontecendo. A segunda seria, no quadro de tal entendimento, a disposição comum dos dois sócios maiores de criar condições mais favoráveis às áreas menos favorecidas, de modo a atenuar as atuais assimetrias, algo no espírito do que há tempos vêm fazendo os países que criaram a Comunidade Econômica Européia. Sem mecanismos compensatórios capazes de atrair de forma duradoura os sócios menores, a solidez do bloco estará sempre ameaçada, como ilustrado pelas já mencionadas declarações do presidente Tabaré Vasquez.

Tudo indica que nenhuma das duas condiçóes venha a ser satisfeita com facilidade ou rapidez. Caberia considerar, portanto, aquilo que - embora não desistindo formalmente de preencher aquelas duas pré-condições - poderemos fazer para irmos construindo uma base regional mais sólida. Não podemos, 
entretanto, partir da premissa de que tal base regional depende de alguma estrutura multinacional sul-americana - que já vimos ser pouco viável, pelo menos num futuro previsível, ainda que limitada ao Mercosul.

Assim, sem prejuízo dos esforços necessários para aprofundar e fortalecer econômica e politicamente o Mercosul, deveríamos atuar bilateralmente, tratando de usar o considerável poder de atração regional da economia brasileira. Isso envolveria oferecer - em termos de reciprocidade relativa ou, em alguns casos, mesmo sem reciprocidade - condições favoráveis de acesso ao nosso mercado a um certo número (a maioria?) dos nossos vizinhos sul-americanos. A principal preocupação não seria com a reciprocidade comercial, mas sim com problemas como regras de origem (para limitar os free riders), com um mínimo de seletividade nas concessões (produtos sensíveis, por exemplo) e com o estabelecimento de uma rede de infra-estrutura de transporte (terrestre e fluvial) e energética, de modo a viabilizar a desejada expansão de comércio e o fortalecimento de laços econômicos e humanos com nossos vizinhos.

Em última análise, tratar-se-ia de abandonar a idéia de um grande projeto multinacional sul-americano em favor de uma aposta - a um tempo ousada e generosa - na capacidade de competição regional da economia brasileira, tanto no comércio de bens como no de serviços, inclusive com a participação de bancos e companhias brasileiras de construção civil naquela rede de infraestrutura. O benefício - para nós como para nossos parceiros em tais acordos bilaterais - derivaria do entrelaçamento de interesses comuns de caráter bilateral. A sinergia derivada da justaposição de tais interesses poderia contribuir para a eventual formação de algum arranjo plurilateral sul-americano ou de esquemas sub-regionais de cooperação e integração. Nenhum desses desenvolvimentos seria, porém, essencial à consecução do desejado objetivo de aprofundar a complementaridade de interesses entre os países sul-americanos, o que deveria facilitar a coordenação de suas respectivas posições e atuações na cena mundial.

Como país de maior peso econômico e demográfico na área e ponto focal desses vários acordos, o Brasil tenderia a tornar-se a peça-chave desse projeto de aproximação regional, sem o recurso, pelo menos no futuro próximo, a uma estrutura institucional disciplinadora ou ao estabelecimento de um sistema multilateral de integração econômica da América do Sul em seu conjunto.

A idéia de uma liderança brasileira desapareceria, assim, de nosso discurso político ou de eventuais projetos brasileiros de âmbito regional. $\mathrm{Na}$ medida em que ainda existisse na prática, tal noção derivaria das condiçôes objetivas criadas por iniciativas limitadas que, se bem sucedidas, iriam no sentido do já mencionado pensamento de John Lewis Gaddis de conseguir que outros queiram o que o líder quer e não apenas que façam o que ele deseja seja feito. Não estaríamos, pois, ignorando o peso específico do Brasil na América do Sul ou o fato de que uma base regional seria um elemento importante de nossa 
política internacional. Estaríamos simplesmente reconhecendo o fato de que tal base teria de ser dada pela única forma de regionalismo continental que realisticamente nos convém - um sul-americanismo que promova os interesses brasileiros dentro do respeito às peculiaridades, sensibilidades e suscetibilidades de nossos vizinhos.

Recebido em 8 de julho de 2006

Aprovado em 18 de setembro de 2006

\section{Resumo}

No artigo aborda-se a questão de em que medida as mudanças ocorridas no cenário nacional e internacional justificam que o Brasil leve adiante uma política externa de potência emergente, no nosso continente e no mundo. Para fundamentar suas conclusões, o artigo considera alguns aspectos relevantes da política mundial desde o fim da Segunda Guerra Mundial, bem como a importância de uma base regional para o exercício de uma política internacional mais assertiva e os desafios que isso nos coloca, particularmente na América do Sul.

\section{Abstract}

The article discusses whether national and international changes occurred since the end of World War II justify Brazil's pursuance of an assertive emerging power foreign policy, both in the American continent and in the world. It examines some relevant features of world policy since the middle of last century, and the challenges posed by Brazil's need to build a strong regional position, especially in South America, as a stepping stone towards a more assertive world policy.

Palavras-chave: Política externa brasileira, potências emergentes, regionalismo continental, integração sul-americana.

Key words: Brazilian foreign policy, emerging powers, world order, American regionalism, South American integration. 